\title{
Subcellular localization and some properties of lipoxygenase activity in human blood platelets
}

\author{
Michel LAGARDE, ${ }^{*} \dagger$ Martine CROSET, ${ }^{*}$ Kalwant S. AUTHI $\ddagger$ and Neville CRAWFORD $\ddagger$ \\ *INSERM U-63, Institut Pasteur, Faculté Alexis Carrel, 69372 Lyon Cedex 2, France, and \\ $\ddagger$ Department of Biochemistry, Royal College of Surgeons, Lincoln's Inn Fields, London WC2A 3PN, U.K.
}

(Received 3 April 1984/Accepted 4 May 1984)

\begin{abstract}
Lipoxygenase activity was measured in human platelet subcellular fractions. From a sonicated platelet preparation, a granule fraction, mixed membranes (surface and intracellular) and cytosol fractions were separated by differential centrifugation. With respect to activities in the sonicated preparation, the lipoxygenase was slightly enriched in both the cytosol and mixed-membrane fractions and consistently deenriched in the granule fractions. Approx. $65 \%$ and $20 \%$ of the total cell enzyme activity were found in the cytosol and mixed membranes respectively, with only $8 \%$ present in the granule fraction. Additionally we measured the lipoxygenase activity in purified surface- and intracellular-membrane subfractions prepared from the mixed membranes by free-flow electrophoresis. There was a slight enrichment in activity in the intracellular membrane fraction compared with that in the mixed membranes, and a depletion of activity in the surface membranes. Characterization of the enzyme activity, i.e. time course, $\mathrm{pH}$-dependence, $\mathrm{Ca}^{2+}$-dependence, $V_{\text {max. }}$ and $K_{\mathrm{m}}$ for arachidonic acid, and the carbon-position specificity for this acid, failed to reveal any significant differences between the membrane-bound and soluble forms of the lipoxygenase. These findings suggest that in human platelets the same lipoxygenase is associated with the membranes as in the cytosol and that the membrane-bound activity predominates in intracellular membrane elements.
\end{abstract}

When human platelets are triggered with most of the conventionally used aggregating agents, arachidonic acid is released from phospholipids (Rittenhouse-Simmons \& Deykin, 1981) and can be subsequently oxygenated by either or both of two major pathways. The first route, the cyclooxygenase/thromboxane synthase pathway, has been well documented (Samuelsson et al., 1976; Smith, 1980), and the second pathway, which involves oxygenation by lipoxygenase, leads to the production of 12-HPETE, which can be further converted into 12-HETE by a glutathionedependent peroxidase (Hamberg et al., 1974; Bryant \& Bailey, 1980; Chang et al., 1982). The role of these latter arachidonic acid derivatives in platelet physiology has not been well defined, but

Abbreviations used: 12-HPETE, 12-hydroperoxyeicosatetraenoic acid; 12-HETE, 12-hydroxyeicosatetraenoic acid; Hepes, 4-(2-hydroxyethyl)-1-piperazineethanesulphonic acid; GSH, reduced glutathione; h.p.l.c., high-performance liquid chromatography.

† To whom reprint requests should be addressed. they have been reported to be inhibitors of prostanoid-induced platelet aggregation (Aharony et al., 1982; Croset \& Lagarde, 1983).

Whereas cyclo-oxygenase activity has been identified as a predominantly intracellular membrane enzyme in human platelets (Carey et al., 1982), the localization of the lipoxygenase is somewhat controversial. In studies with bovine and rat platelets, most of the activity was found in the cytosol compartment by Nugteren (1975) and Chang et al. (1982), whereas in another paper the activity was found to be exclusively localized in a particulate fraction prepared from human platelet homogenates (Ho et al., 1977). The work described in this present study suggests that the lipoxygenase in human platelets is bimodally distributed between the cytosol and membranes, with the former activity, when expressed as a percentage of the total cell activity, very much predominating. Characterization of these enzymes' activities supports the view that the same enzyme is responsible for the expression of lipoxygenase activity in the two subcellular compartments. 


\section{Experimental}

\section{Preparation of platelet subcellular fractions}

Human platelets were isolated from fresh buffy coats provided by donors who had not taken any drug during the previous 10 days or more. Plateletrich plasma was obtained by centrifugation at room temperature for $20 \mathrm{~min}$ at $200 \mathrm{~g}$. It was removed, acidified to pH6.4 with citric acid and centrifuged at $1200 \mathrm{~g}$ for $20 \mathrm{~min}$ at room temperature. The resultant platelet pellet was resuspended in washing buffer $(152 \mathrm{mM}-\mathrm{NaCl} / 4 \mathrm{mM}-$ $\mathrm{KCl} / 3 \mathrm{~mm}$-EDTA/10mm-Hepes, $\mathrm{pH} 7.2$ ) and centrifuged again for $15 \mathrm{~min}$ under the same conditions. The platelets were carefully suspended in a sorbitol buffer $(0.34 \mathrm{M}$-sorbitol/10 mM-Hepes, $\mathrm{pH} 7.2$ ) and sonicated as reported previously (Menashi et al., 1981). The sonicated preparation was subjected to either differential centrifugation or density-gradient centrifugation. The former was the routine procedure, and the latter was used only for the further membrane subfractionation by freeflow electrophoresis. In the differential-centrifugation procedure, the sonicated material was centrifuged at $13000 \mathrm{~g}$ for $20 \mathrm{~min}$ at $4^{\circ} \mathrm{C}$ to pellet a granule fraction. This fraction included mitochondria, $\alpha$-granules, lysosomes and 5-hydroxytryptamine-storage granules. The supernatant was carefully removed from above the granule pellet and centrifuged at $100000 \mathrm{~g}$ for $90 \mathrm{~min}$ at $4^{\circ} \mathrm{C}$ to sediment a mixed membrane fraction (this includes membranes of both surface and intracellular origin). The supernatant from this high-speed centrifugation represented the cytosol. For further fractionation of the mixed membranes into discrete subfractions of surface and intracellular membranes, the sonicated material was applied to a linear 1-3.5 $\mathrm{M}$-sorbitol density gradient (in $10 \mathrm{mM}$ Hepes, $\mathrm{pH} 7.2$ ) and centrifuged at $42000 \mathrm{~g}$ for $90 \mathrm{~min}$ at $4^{\circ} \mathrm{C}$. The mixed membrane fraction, which was located in the low-density region of the gradient, well separated from the granular organelles, was removed and centrifuged on to a cushion of $3.5 \mathrm{M}$-sorbitol $/ 10 \mathrm{~mm}$-Hepes, $\mathrm{pH} 7.2$, at $100000 \mathrm{~g}$ for $90 \mathrm{~min}$ at $4^{\circ} \mathrm{C}$. After resuspension this membrane fraction was applied to the chamber of the free-flow-electrophoresis apparatus model VAP5 (Bender Hobein, Munich, Germany) and processed exactly by the procedure of Menashi et al. (1981). In developing this procedure it was found that membrane vesicles taken from the gradient gave a more uniform charge expression than did membranes separated by differential centrifugation, and in consequence a better resolution in electrophoresis.

Extensive characterization of the membrane subfractions has been reported previously, and particularly with respect to lipid, phospholipid, fatty acid and polypeptide composition, as also for the phospholipid-modifying and prostanoid-synthesizing enzymes (Menashi et al., 1981; Lagarde et al., 1981; Carey et al., 1982). Briefly, the identification of their site of origin in the platelet depended, in the case of the surface membrane, on (a) the presence in the free-flow-electrophoresis profile of a peak enriched with ${ }^{125}$ I-labelled Lens culinaris lectin which had been applied to the whole cell before fractionation, (b) an electrophoretic-mobility change after neuraminidase treatment at the whole-cell level, and $(c)$ the presence of, and enrichment of, adenylate cyclase activity. The intracellular membrane fractions were identified by exclusive localization of the endoplasmic-reticulum enzyme NADH:cytochrome $c$ reductase, leucine aminopeptidase, phospholipase $\mathrm{A}_{2}$ and a range of prostanoidsynthesizing enzymes. This intracellularmembrane peak also showed no change in electrophoretic mobility when membranes from whole platelets, untreated or treated with neuraminidase, were directly compared.

\section{Lipoxygenase assay}

Unless otherwise specified in the Figure and Table legends, portions of the platelet subfractions (approx. $0.5 \mathrm{mg}$ of protein) were incubated in $0.5 \mathrm{ml}$ of Tyrode buffer $(136 \mathrm{mM}-\mathrm{NaCl} / 12 \mathrm{~mm}$ $\mathrm{NaHCO}_{3} / 2.7 \mathrm{~mm}-\mathrm{KCl} / 1 \mathrm{~mm}-\mathrm{MgCl}_{2} / 0.42 \mathrm{~mm}-\mathrm{Na}-$ $\mathrm{H}_{2} \mathrm{PO}_{4} / 5 \mathrm{~mm}$-Hepes/5.5 mM-glucose, $\mathrm{pH} 7.4$ ) containing $0.1 \mathrm{mM}-\left[{ }^{14} \mathrm{C}\right]$ arachidonic acid $(1 \mathrm{Ci} / \mathrm{mol})$ in $0.5 \%$ ethanol for $2 \mathrm{~min}$ at $37^{\circ} \mathrm{C}$. All incubation mixtures included $0.2 \mathrm{~mm}$-aspirin, a concentration which is known to inhibit the platelet cyclo-oxygenase without significantly affecting the peroxidase activity (Siegel et al., 1979b). To facilitate full peroxidase activity, the incubation mixtures also contained GSH; $1.0 \mathrm{mM}$ for the membrane fractions and $0.1 \mathrm{mM}$ for the cytosol. The incubations were terminated by acidification to $\mathrm{pH} 3$ with $\mathrm{HCl}$, and the lipids were extracted into $10 \mathrm{vol}$. of diethyl ether.

\section{Analysis of lipoxygenase products}

After the lipid extract was dried down, it was resolubilized in a small volume of diethyl ether, and the lipids were separated by t.l.c. on silica-gel $\mathrm{G}$ at $4^{\circ} \mathrm{C}$ with hexane/diethyl ether/acetic acid (60:40:1, by vol.). The remaining arachidonic acid substrate $\left(R_{\mathrm{F}} 0.6\right)$ and its major metabolite 12HETE $\left(R_{\mathrm{F}} 0.37\right)$ were either scraped off the plate and counted for radioactivity by liquid scintillation or detected and quantified with an integrating scanner (Boukhchache \& Lagarde, 1982). With high concentrations of arachidonic acid, as used in the determination of $K_{\mathrm{m}}$, HPETE, the hydroperoxy precursor of HETE, could be identified $\left(R_{\mathrm{F}}\right.$ 
0.45) and also the compound 10-hydroxy-11,12 epoxyeicosatrienoic acid $\left(R_{\mathrm{F}} 0.30\right)$ as reported by Walker et al. (1979). When appropriate, therefore, all three oxygenated compounds were taken into account in the calculation of lipoxygenase activities.

The carbon position of the hydroxy derivative was checked by h.p.l.c. For this purpose the HETE spot was scraped off the plate, extracted three times with diethyl ether and subjected to reversephase h.p.l.c. on a $\mathrm{C}_{18} 5 \mu \mathrm{m}$-particle column with methanol/water, pH3 $(37: 13, \mathrm{v} / \mathrm{v})$ as a solvent (Croset \& Lagarde, 1983).

\section{Results and discussion}

An incubation time of $2 \mathrm{~min}$ was chosen since it was found that the production of oxygenated derivatives from arachidonic acid by the platelet fractions was substantially linear with time up to this period (Fig. 2). The activities measured in the various platelet subcellular fractions are shown in Table 1. In comparison with the activity in the sonicated preparation, the specific activities in both the membranes and the cytosol were slightly enriched, whereas the activities in the granule fractions were consistently, and substantially, lower than in the sonicated preparation. With respect to the percentage distribution of the enzyme, about $65 \%$ and $20 \%$ of the total activity in the sonicated preparation could be accounted for by the cytosol and membrane fractions respectively. Routinely the activity of the enzyme was measured in the presence of GSH, which is a cofactor for the associated peroxidase. This addition significantly decreased the variation in the measurements, and, although higher activities could be recorded in the absence of GSH (results not shown), and especially in the membrane fractions, this effect was considered to be due to enzyme potentiation by the 12-HPETE formed in

Table 1. Lipoxygenase activity in platelet subfractions Specific activities and percentages of total activity are expressed as means \pm S.D. from six different platelet preparations. Assays were performed as described in the Experimental section.

\begin{tabular}{|c|c|}
\hline \multicolumn{2}{|c|}{ Activity } \\
\hline $\begin{array}{l}\text { ( } \mathrm{nmol} / \mathrm{min} \text { per } \\
\mathrm{mg} \text { of protein) }\end{array}$ & ( $\%$ distribution) \\
\hline $\begin{array}{l}3.0 \pm 1.6 \\
3.8 \pm 1.1 \\
4.0 \pm 2.4 \\
1.2 \pm 0.8\end{array}$ & $\begin{array}{c}100 \\
64.9 \pm 12.9 \\
21.1 \pm 6.3 \\
8.3 \pm 9.0\end{array}$ \\
\hline Recove & $=93.5 \%$ \\
\hline
\end{tabular}

the reaction (Siegel et al., 1979a). The lipoxygenase activity in the membrane was not significantly decreased by extensive washing or by further sonication. In a typical experiment the activity was $4.9(\mathrm{nmol} / \mathrm{min}$ per $\mathrm{mg}$ of protein) before washing, 4.2 after washing and 4.5 after further sonication and washing. It is therefore considered unlikely that the membrane-bound enzyme is an artefact of cytosol contamination. A similar distribution of activity has been reported for the epidermal 12lipoxygenase (Ruzicka et al., 1983), where in this case the distribution was approx. 2:1 cytosol:microsomal fraction.

The activity of the enzymes in both the cytosol and membranes was further characterized for $\mathrm{pH}$ dependence and kinetics. Although there are slight differences in the $\mathrm{pH} /$ activity profiles for the cytosolic and membrane-bound lipoxygenase, a $\mathrm{pH}$ around neutral seems optimal for both enzymes (Fig. 1). The differences in the $\mathrm{pH} /$ activity profile could perhaps be explained on the basis of different micro-environments for the membrane and cytosolic enzymes and does not necessarily imply that two different enzymes are present in the

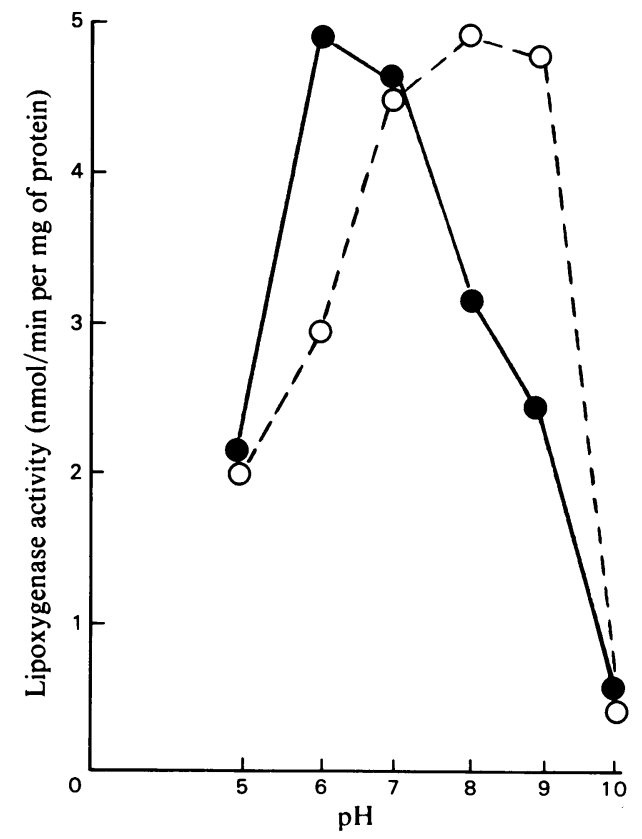

Fig. 1. pH-dependence of the lipoxygenase activity of the mixed membranes $(O)$ and cytosol $(O)$ fractions For the different $\mathrm{pH}$ conditions, the incubations were adjusted with a citrate/phosphate/borate buffer (Teorell \& Stenhagen, Documenta Geigy, Scientific Tables, 6th edn., p. 314). The results are mean values derived from two different platelet preparations. 
cell. A similar $\mathrm{pH} /$ activity profile was presented by Wallach \& Brown (1981), who studied the human platelet lipoxygenase activity in solubilized intact cells. In the present studies the time course for the activity was essentially the same for the lipoxygenase in the two subcellular compartments, reaching plateaux after about $10 \mathrm{~min}$ (Fig. 2). The initial rates for the two enzymes, however, consistently differed, with the membrane-bound form operating at approximately twice the rate of the soluble form. The enzyme associated with the membranes may more effectively produce 12HPETE and 12-HETE during the early stages of platelet aggregation.

It has been reported that certain lipoxygenase metabolites, and in particular the 12-hydroxy derivatives from arachidonic acid, may have a regulatory or modulating role in aggregation induced by both prostaglandin $\mathrm{H}_{2}$ and thromboxane $\mathrm{A}_{2}$ (Aharony et al., 1982; Croset \& Lagarde, 1983) and the kinetic studies by Samuelsson (1977) have demonstrated that the prostaglandin $\mathrm{H}_{2}$ /thromboxane $\mathrm{A}_{2}$ ratio reaches a peak at or around $30 \mathrm{~s}$ when platelets are aggregated by a haemostatic activator. If such is the case, the membrane-bound lipoxygenase may be a more efficient regulator of platelet functions under physiological conditions.

The apparent $K_{\mathrm{m}}$ values for the two enzymes are quite similar, $7.2(n=2)$ and $8.7(n=2)$ for the cytosol and membrane enzymes respectively, sup-

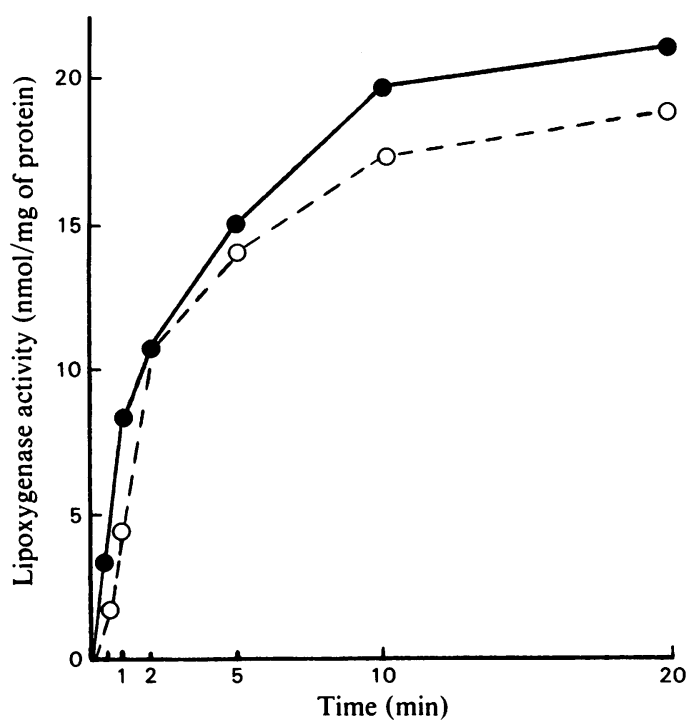

Fig. 2. Time-course of the lipoxygenase activity in the mixed membranes $(O)$ and cytosol $(O)$

The results are mean values derived from three different platelet preparations. porting the view that the same enzyme is bimodally distributed. These $K_{\mathrm{m}}$ values are within the range for the lipoxygenases studied by other workers, i.e. $18 \mu \mathrm{M}$ for the enzyme solubilized from intact human platelets (Wallach \& Brown, 1981) and $4 \mu \mathrm{M}$ for human platelet cytosol lipoxygenase activity measured by oxygen consumption (Aharony et al., 1984).

Using h.p.l.c. for the separation of the monohydroxy derivatives produced from three different fatty acid precursors of prostaglandins during incubation with intact human platelets, we have reported (Lagarde et al., 1984) the formation of small quantities of metabolites which in each case coincide in the h.p.l.c. profiles with the authentic 15-hydroxy derivative of the respective precursor fatty acid. The metabolite proportions differ, however, for each precursor. In the present study we have analysed the monohydroxy acids produced from arachidonic acid after incubation with platelet cytosol and membrane fractions. The h.p.l.c. profiles from cytosol and membrane incubation (Fig. 3) show approximately the same proportion of a metabolite which has the same mobility as 15-HETE, the ratio of this to 12-HETE being approx. 1:9 for both fractions. This finding does not, of course, identify a 15-lipoxygenase present in human platelets, since it could be accounted for by a small amount of leucocyte contamination of the platelet preparation. Leucocytes, and particularly small lymphocytes, are difficult to remove totally from platelet preparations, and are relatively rich in this enzyme (Narumiya et al., 1981). The consistency in relative amounts of the two metabolites does, however, add substance to our view that the cytosol and membrane-bound lipoxygenase activities of the platelet are essentially identical. Finally we have investigated the $\mathrm{Ca}^{2+}$-dependence of the cytosol and membrane enzymes. This is also a controversial issue, since it is generally accepted that purified lipoxygenase is insensitive to $\mathrm{Ca}^{2+}$ (Lands, 1979), but a subsequent report by Maclouf et al. (1982) revealed that in intact platelets exposed to exogenous arachidonic acid the formation of HETE was increased in the presence of the $\mathrm{Ca}^{2+}$ antagonist 3,4,5-trimethoxybenzoic acid 8(diethylamino)-octyl ester (TMB-8). In the present studies neither the cytosolic nor the membrane lipoxygenase were affected by $\mathrm{Ca}^{2+}$ chelation with EGTA, by addition of $\mathrm{Ca}^{2+}$ or by increasing quantities of trifluoperazine, a calmodulin inhibitor (Table 2). It seems therefore that the platelet lipoxygenase (mainly 12-lipoxygenase) is unaffected by changes in $\mathrm{Ca}^{2+}$ concentration, which is in sharp contrast with the leucocyte lipoxygenase, which has been clearly shown to be stimulated by ionophores and/or exogenous $\mathrm{Ca}^{2+}$ 

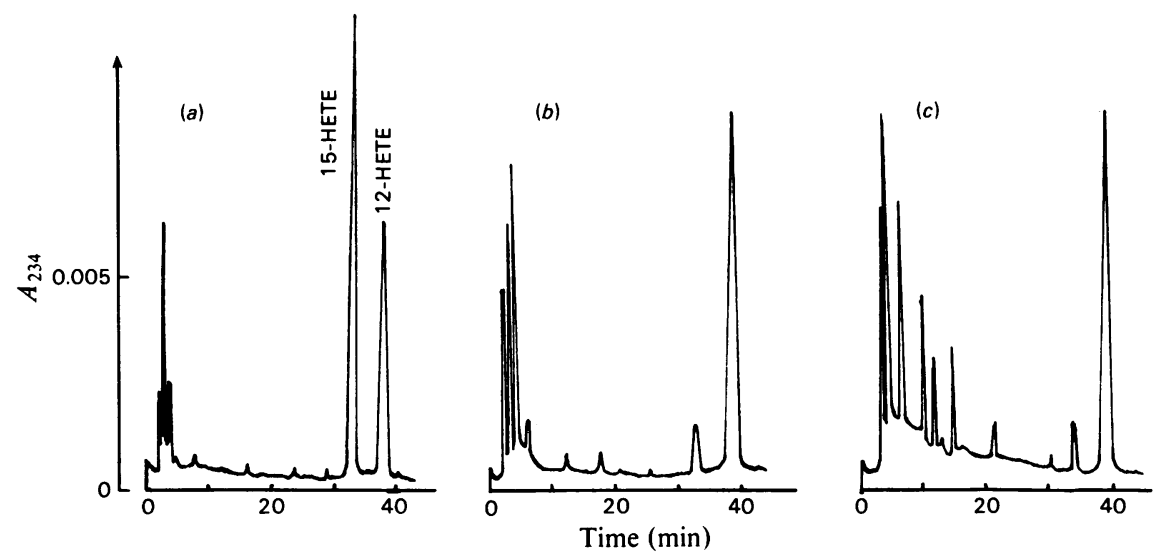

Fig. 3. Identification of the metabolites of lipoxygenase activity in the cytosol $(b)$ and mixed membrane $(c)$ For comparison the h.p.l.c. profile $(a)$ includes standard preparations of 15- and 12-HETE produced by soya-bean and platelet lipoxygenase activities respectively.

Table 2. $\mathrm{Ca}^{2+}$-dependence of lipoxygenase activity Specific activities were measured in the cytosol fractions $(C)$ and mixed membranes $(M)$ prepared from two different platelet preparations (1 and 2). Abbreviation: TFP, trifluoperazine. Incubation conditions are as described in the Experimental section.

Lipoxygenase activity ( $\mathrm{nmol} / \mathrm{min}$ per $\mathrm{mg}$ of protein)

$\begin{array}{lllll}\text { Control } & 3.5 & 3.6 & 3.6 & 3.3 \\ \text { EGTA }(2 \mathrm{mM}) & 4.1 & 3.9 & 3.4 & 3.2 \\ \mathrm{CaCl}_{2}(1 \mathrm{mM}) & 3.8 & 3.7 & 4.9 & 4.3 \\ \text { TFP }(1 \mu \mathrm{M}) & 4.0 & 3.4 & 4.9 & 4.2 \\ \text { TFP }(10 \mu \mathrm{M}) & 3.8 & 3.1 & 4.3 & 3.0 \\ \text { TFP }(100 \mu \mathrm{M}) & 2.9 & 3.0 & 4.8 & 4.3\end{array}$

(Borgeat \& Sirois, 1981; Parker \& Aykent, 1982). These results again demonstrate that there is essentially no difference between the cytosol and membrane lipoxygenases. Since the lipoxygenase activity associated with the membranes was apparently tightly bound, attempts were made to investigate its distribution in surface- and intracellular-membrane subfractions prepared by freeflow electrophoresis. The activity (nmol/min per mg of protein; means \pm S.D., $n=6$ ) in the intracellular-membrane fraction $(3.0 \pm 0.8)$ was significantly higher than that in the surface membranes $(1.8 \pm 0.6)$, the latter being substantially depleted in activity compared with that found in the starting material for the electrophoretic separation, i.e. the mixed-membrane fraction $(2.8 \pm 1.0)$.

In conclusion, therefore, the membrane-bound lipoxygenase of human platelets, characterized as largely a 12-lipoxygenase, is unaffected by $\mathrm{Ca}^{2+}$, has a $\mathrm{pH}$ optimum between $\mathrm{pH} 6$ and 7 and is predominantly localized in the intracellular membranes. We have previously demonstrated that the phospholipid-modifying enzyme phospholipase $\mathbf{A}_{2}$ and the diacylglycerol lipase are also localized in these intracellular membranes and that the constituent phospholipids are rich in arachidonic acid (Lagarde et al., 1981, 1982). Moreover, these intracellular membranes are also the site of prostaglandin $\mathrm{H}_{2}$ /thromboxane $\mathrm{A}_{2}$ formation in the platelet (Gerrard et al., 1976; Carey et al., 1982). One might therefore present the concept of a restricted and common location in the platelet of enzyme systems for producing not only proaggregatory prostanoids (prostaglandin $\mathrm{H}_{2}$ and thromboxane $\mathrm{A}_{2}$ ), but also eicosanoid antagonists (12-HPETE and 12-HETE), through which the regulation of platelet behaviour may depend on different time courses for their production.

This work was partially supported by INSERM (grant CRL 825043). We gratefully acknowledge financial support to K. S. A. from the British Heart Foundation.

\section{References}

Aharony, D., Smith, J. B. \& Silver, M. J. (1982) Biochim. Biophys. Acta 718, 193-200

Aharony, D., Smith, J. B. \& Silver, M. J. (1984) in The Leukotrienes (Cahkvin, L. W. \& Bailey, D. M., eds.), pp. 103-123, Academic Press, New York

Borgeat, P. \& Sirois, P. (1981) J. Med. Chem. 24, 121-126

Boukhchache, D. \& Lagarde, M. (1982) Biochim. Biophys. Acta 713, 386-392

Bryant, R. W. \& Bailey, J. M. (1980) Biochem. Biophys. Res. Commun. 92, 268-276

Carey, F., Menashi, S. \& Crawford, N. (1982) Biochem. J. 204, 847-851 
Chang, W. C., Nakao, J., Orimo, H. \& Murota, S. (1982) Biochem. J. 202, 771-776

Croset, M. \& Lagarde, M. (1983) Biochem. Biophys. Res. Commun. 112, 878-883

Gerrard, J. M., White, J. G., Rao, G. H. R. \& Townsend, D. W. (1976) Am. J. Pathol. 83, 283-298

Hamberg, M., Svensson, J. \& Samuelsson, B. (1974) Proc. Natl. Acad. Sci. U.S.A. 71, 3824-3828

Ho, P. P. K., Walters, P. \& Sullivan, H. R. (1977) Biochem. Biophys. Res. Commun. 76, 398-405

Lagarde, M., Menashi, S. \& Crawford, N. (1981) FEBS Lett. 124, 23-26

Lagarde, M., Guichardant, M., Menashi, S. \& Crawford, N. (1982) J. Biol. Chem. 257, 3100-3104

Lagarde, M., Croset, M., Boukhchache, D., Greffe, A., Dechavanne, M. \& Renaud, S. (1984) Prostaglandins, Leukotrienes Med. 13, 61-66

Lands, W. C. M. (1979) Annu. Rev. Physiol. 41, 633652

Maclouf, J., de la Baume, H., Levy-Toledano, S. \& Caen, J. P. (1982) Biochim. Biophys. Acta 711, 377-385

Menashi, S., Weintroub, H. \& Crawford, N. (1981) J. Biol. Chem. 256, 4095-4101

Narumiya, S., Salmon, J. A., Cottee, F. H., Weatherley, B. C. \& Flower, R. J. (1981) J. Biol. Chem. 256, 95839592
Nugteren, D. H. (1975) Biochim. Biophys. Acta 380, 299307

Parker, C. W. \& Aykent, S. (1982) Biochem. Biophys. Res. Commun. 109, 1011-1016

Rittenhouse-Simmons, S. \& Deykin, D. (1981) in Platelets in Biology and Pathology (Gordon, J. L., ed.), vol. 2, pp. 349-372, Elsevier/North-Holland, Amsterdam

Ruzicka, T., Vitto, A. \& Printz, M. P. (1983) Biochim. Biophys. Acta 751, 369-374

Samuelsson, B. (1977) in Prostaglandins in Hematology (Silver, M. J., Smith, J. B. \& Kocsis, J. J., eds.), pp. 110, Spectrum Publications, New York

Samuelsson, B., Hamberg, M., Malmsten, C. \& Svensson, J. (1976) Adv. Prostaglandin Thromboxane Res. 5, 737-746

Siegel, M. I., McConnel, R. T., Abrahams, S. L., Porter, N. A. \& Cuatrecasas, P. (1979a) Biochem. Biophys. Res. Commun. 89, 1273-1280

Siegel, M. I., McConnel, R. T. \& Cuatrecasas, P. (1979b) Proc. Natl. Acad. Sci. U.S.A. 76, 3774-3778

Smith, J. B. (1980) Am. J. Pathol. 94, 743-804

Walker, I. C., Jones, R. L. \& Wilson, N. H. (1979) Prostaglandins 18, 173-178

Wallach, D. P. \& Brown, V. R. (1981) Biochim. Biophys. Acta 663, 361-372 